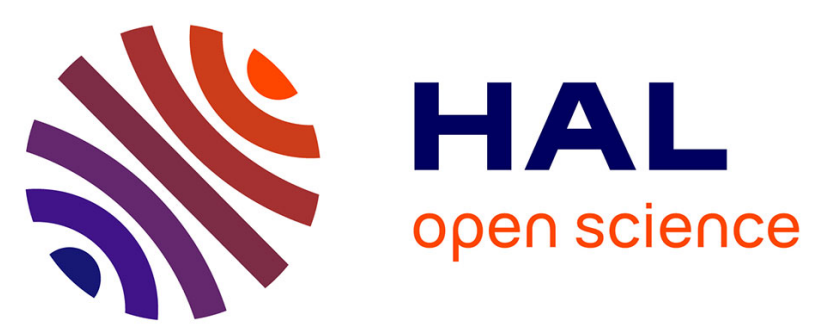

\title{
OPTIMUM PROCESS CONDITIONS FOR STABLE AND EFFECTIVE OPERATION OF A FLUIDIZED BED CVD REACTOR FOR POLYCRYSTALLINE SILICON PRODUCTION
}

\author{
T. Kojima, O. Morisawa
}

\section{To cite this version:}

T. Kojima, O. Morisawa. OPTIMUM PROCESS CONDITIONS FOR STABLE AND EFFECTIVE OPERATION OF A FLUIDIZED BED CVD REACTOR FOR POLYCRYSTALLINE SILICON PRODUCTION. Journal de Physique IV Proceedings, 1991, 02 (C2), pp.C2-475-C2-482. 10.1051/jp4:1991258 . jpa-00249848

HAL Id: jpa-00249848 https://hal.science/jpa-00249848

Submitted on 1 Jan 1991

HAL is a multi-disciplinary open access archive for the deposit and dissemination of scientific research documents, whether they are published or not. The documents may come from teaching and research institutions in France or abroad, or from public or private research centers.
L'archive ouverte pluridisciplinaire HAL, est destinée au dépôt et à la diffusion de documents scientifiques de niveau recherche, publiés ou non, émanant des établissements d'enseignement et de recherche français ou étrangers, des laboratoires publics ou privés. 
Colloque C2, suppl. au Journal de Physique II, Vol. 1, septembre 1991

\title{
OPTIMUM PROCESS CONDITIONS FOR STABLE AND EFFECTIVE OPERATION OF A FLUIDIZED BED CVD REACTOR FOR POLYCRYSTALLINE SILICON PRODUCTION
}

\author{
T. KOJIMA and O. MORISAWA \\ Department of Industrial Chemistry, Seikei university, \\ 3-3-1 Kichijojikita-machi, Musashino-shi, Tokyo 180, Japan
}

\begin{abstract}
The fluidized bed CVD process for the polycrystalline silicon production is considered to be the most attractive alternative to the conventional bell-jar process. The employment of a reaction path starting from monosilane has various merits over the conventional reaction path starting from trichlorosilane. In the present study, chemical vapor deposition of polycrystalline silicon on seed particles was conducted in a experimental fluidized bed reactor by thermal decomposition of monosilane diluted with hydrogen. The bed temperature was gradually increased and the conversion at the temperature was measured. The apparent first order reaction rate constant of monosilane pyrolysis in the bed was determined and the activation energy was found to be almost the same as that of heterogeneous deposition reaction rate constant. Optimum process conditions for stable and effective operation were determined. Lastly the continuous operation was conducted for more than $100 \mathrm{~min}$. without any trouble and with the least fines elutriation under the optimum condition determined above.
\end{abstract}

\section{1.-Introduction.}

Polycrystalline silicon has so far been manufactured by hydrogen reduction of trichlorosilane using a bell-jar reactor in the Siemens Process. The Komatsu process also employs almost the same type of reactor as that in the Siemens Process but polycrystalline silicon is produced by thermal decomposition of monosilane. The deposition on rods in a bell jar reactor employed in the Siemens process has the following problems: (1) low thermal efficiency and high electrical cost because of the cooling of the bell jar, naturally or forcibly, in order to prevent the deposit on the bell-jar reactor wall and to prevent fines formation by gas phase homogeneous reaction, (2) low reactor capacity due to relatively small reaction interface of rods per unit volume of the bell-jar reactor, (3) complicated configuration of rods and gas injector and difficulties in scale up, and (4) inevitable batch operation and no possibility of continuous operation.

Recently there has been a demand for silicon with higher purity than that from conventional processes. The employment of a reaction path starting from monosilane has various merits over the conventional reaction path starting from trichlorosilane. The significant advantages have been emphasized as follows /1/; (1) higher one pass yield of silicon from monosilane gas under lower temperature than that from trichlorosilane gas in the reactor, (2) no necessity of recycle of reactant (only hydrogen is recycled as diluent) because of the absence of byproduct and $100 \%$ of thermodynamical conversion, as a result, lower accumulation of impurities in the recycle gas, "(3) absence of corrosive hydrogen chloride, (4) easy purification of 
monosilane due to the low boiling point of monosilane, as a result, higher purity of produced poly-Si from monosilane than that from trichlorosilane.

The fluidized bed process for the polycrystalline silicon production is considered to be the most attractive alternative to the conventional be11-jar process. The application of a fluidized bed reactor for silicon production is advantageous over the conventional rod reactor because of: (1) high thermal efficiency (2) continuous operation and high throughput. The produced silicon particles, which are easy to feed into the crucible, enable the continuous operation of the CZ process for single crystalline silicon production. The application to poly-Si production from trichlorosilane has been tried by NEDO (New Energy Development Organization /2/ and from monosilane by UCC/JPL (Union Carbide Corp./ Jet Propulsion Laboratory) /3,4/. In the NEDO process, the byproduct of silicon tetrachloride is aimed to be recycled to produce trichlorosilane. By these developments, the improvement of the thermal efficiency by the application of the fluidized bed reactor has been demonstrated. However, many problems have been exposed; deposition of silicon on the reactor surface, breakage of the fluidized bed, and clogging of particles in the bed.

Hsu et al. /5/ have reported the results for fluidized bed CVD of silicon from monosilane. The measured percentage of fines elutriation was generally below $10 \%$ of the silicon-in-silane feed (around $8 \%$ at silane concentration $40-50 \%$ ). They concluded that the optimal operating temperature from the view point of fines elutriation and morphology is $973 \mathrm{~K}$ and suggested that high silane concentration ( $>50 \%)$ feed can be used without excessive fines generation within the vicinity of the above operating condition. Recently, Ethyl Co. Ltd. has begun to commercially produce polycrystalline silicon by monosilane decomposition in a fluidized bed reactor. Details of the process, especially the reactor configuration have not been published excepting some information on an outline of the process and standard operational conditions of the reactor $/ 6 /$.

Since the formation of fines is highly dependent on the relative importance of CVD reaction rate and homogeneous nucleation rate within interparticle spaces of the bed, a separate evaluation of the two reaction rates under conditions pertinent to practical operation is needed. The present authors /7/ conducted separate evaluation of both homogeneous and heterogeneous reaction rates over the temperature ranging from $823 \mathrm{~K}$ to $973 \mathrm{~K}$ and over a relatively wide range of monosilane concentration in both argon and hydrogen as diluents: The kinetic expression was obtained as a sum of homogeneous nucleation rate and CVD reaction rate, the latter being a function of surface area per unit particulate volume.

In the present series of investigations, the polycrystalline silicon production by monosilane pyrolysis is conducted in a batch fluidized bed reactor packed with seed silicon particles. In a previous paper $/ 8 /$, the results on the monosilane conversion, fines elutriation, and clogging phenomena in the fluidized bed CVD reactor using argon as diluent was reported. In the commercial process of polysilicon production by monosilane pyrolysis, hydrogen gas should be employed as the diluent because only hydrogen is produced as byproduct. In a previous paper, the effects of the properties of diluent gas were also measured and discussed $/ 9 \%$

In the present paper, the processes of determination of the optimum operation condition for high inlet silane concentration, high silane conversion and low fine silicon formation without clogging phenomena in hydrogen diluent, by varying bed temperature, grid structure and gas flow rate, are described. In addition, the details of continuous operation conducted for more than $100 \mathrm{~min}$ without any trouble under the optimum condition determined above, are described.

\section{2.-Experimental.}

Details of the experimental fluidized bed reactor made of SUS 316 tube with 50mm ID 
are shown in Fig. 1. The 1ength of the reactor was $750 \mathrm{~mm}$ (type "S") or $825 \mathrm{~mm}$ (type "L"). The surface of the upper flange of the reactor was located $310 \mathrm{~mm}$ above the center of the electric furnace throughout the runs. The reactor was equipped with an upper expanded part with $114.3 \mathrm{~mm}$ ID. This part was not thermally insulated (cooled by air). Two of the most characteristic gas injectors tested in the previous study /8/ were employed. The details of the gas injectors are shown in Fig. 2. The gas injector " $N$ " was composed of a water cooled nozzle with $2 \mathrm{~mm}$ opening for silane introduction and a cone-shaped gas distributor with eighteen $0.5 \mathrm{~mm}$ ID holes for hydrogen introduction. The gas injector "P" was composed of $2 \mathrm{~mm}$ thick sintered SUS distributor cooled by water, and premixed gas of monosilane and hydrogen was introduced.
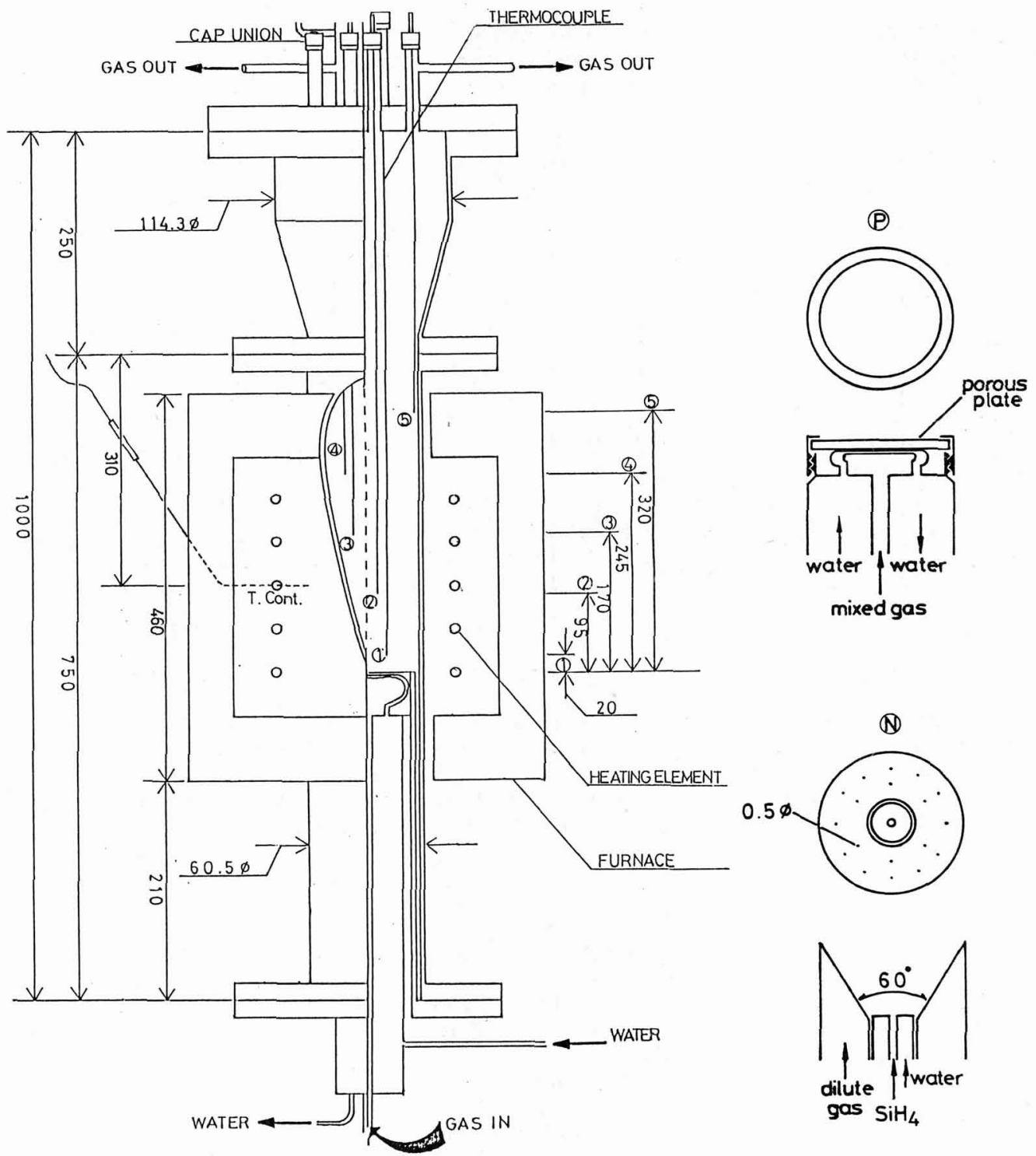

Fig. 1.- Fluidized bed CVD reactor.

Fig. 2- Detail design of gas injectors employed. 
The top surface of these gas injectors was located at $375 \mathrm{~mm}$ (type "A") or $225 \mathrm{~mm}$ (type "B") above the top level of the lower flange of the reactor. Therefore the top surface of the injector was located $215 \mathrm{~mm}$ below the center of the electrical furnace for type "SB" and $140 \mathrm{~mm}$ for "LA". Five CA thermocouples were inserted at $20,95,170,245$, and $320 \mathrm{~mm}$ above the distributor plate. The electric furnace was also equipped with a $\mathrm{CA}$ thermocouple placed at the external surface of the reactor at the middle height of the furnace for the temperature control.

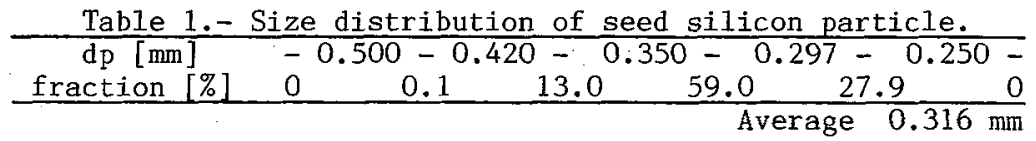

Seed silicon particles employed were metal grade silicon (Yamaishi Kinzoku, purity 98.5\%). The size distribution of the seed particles is shown in Table 1 . The initial packed amount of seed was $850-855 \mathrm{~g}$ and the initial static bed height was around $280 \mathrm{~mm}$.

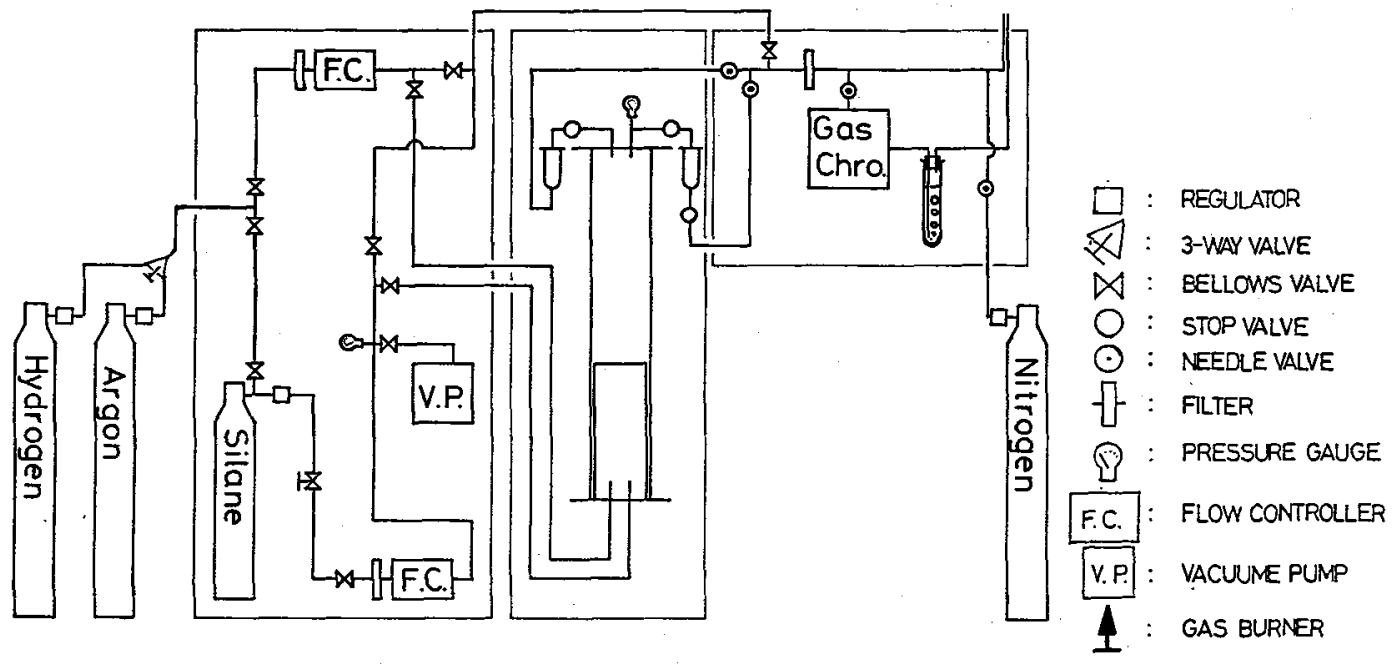

Fig. 3.- Experimental flow sheet.

The flow sheet of the present experiment is shown in Fig. 3. The bed was heated in the argon flow and after the temperature attained a desired value, hydrogen was introduced instead of argon through both lines with flow rates adjusted by mass flow controllers. Then monosilane with an adjusted flow rate was introduced instead of hydrogen through the lower line in Fig. 3. The scope of the experimental runs is shown in Table 2.

Table 2.- Scope of Runs

\begin{tabular}{|c|c|c|c|c|c|}
\hline \multirow{2}{*}{\multicolumn{4}{|c|}{ run react. T $\mathrm{Q}_{298 \mathrm{H}} \mathrm{Q}_{298 \mathrm{~S}} \mathrm{Cs}$}} & & \\
\hline & \multicolumn{2}{|c|}{ No. \& dis. $\mathrm{K}$} & & & \\
\hline \multirow{2}{*}{\multicolumn{6}{|c|}{018 SBP $-13.31 .8312 .1$}} \\
\hline & & & & & \\
\hline & LAN & - & 15.5 & 2.18 & 12.3 \\
\hline \multirow{2}{*}{$\begin{array}{l}204 A \\
204 B\end{array}$} & SBN & - & 15.5 & 2.18 & 12.3 \\
\hline & $3 \mathrm{SBN}$ & 873 & 6Umfor & r 4Umf & \\
\hline \multirow{2}{*}{$\begin{array}{l}209 A \\
209 B\end{array}$} & LAP & _ & 15.5 & 2.18 & 12.3 \\
\hline & $3 \mathrm{LAP}$ & 873 & 6Umfor & r4Umf & \\
\hline 213 & $\mathrm{LAP}$ & 873 & 5.0 & 3.79 & 43.0 \\
\hline \multicolumn{5}{|c|}{$98 S^{=17.64 \mathrm{l} / \mathrm{min}}$} & $1 / \mathrm{min}$ \\
\hline
\end{tabular}


The changes in the temperature profiles in the bed, and inlet and outlet gas pressures were measured continuously. The produced gas was led to a TCD gas chromatograph (argon carrier, Porapak T) through a filter paper to trap the elutriated and entrained fine powder produced by homogeneous reaction. The gas composition of the outlet gas was analyzed intermittently. In runs 018, 022, 204A and $209 \mathrm{~A}$, the bed temperature was gradually increased and the conversion at the temperature was measured.

In the runs $204 \mathrm{~B}$ and $209 \mathrm{~B}$, the maximum temperature in the bed was almost fixed. However, the silane concentration was varied every ten minutes or so, keeping Uo/Umf (superficial gas velocity/ minimum fluidization gas velocity) at 6 or 4. In these runs, the sum of $\mathrm{Q}_{\mathrm{H}}$ and $2 \mathrm{Q}_{\mathrm{S}}$ was kept constant, because the value of Umf of silane was almost half as much as Umf of hydrogen and after the reaction, two moles of hydrogen is produced from one mol of silane. After changing the concentration, the outlet gas composition varied but gradually attained a steady state. In the following results, only the steady state values of silane conversion for each inlet gas concentration are shown. After the run, the weights of bed particles and fines collected on the filter paper were measured.

\section{3.- General results.}

The freeboard pressure was slightly increased (less than $0.1 \mathrm{~atm}$ ) with the progress of the reaction because of the pressure drop of the fine particles layer on the filter paper. No bed particles were found on the filter. In the exit gas, only produced hydrogen and unreacted monosilane were detected. Therefore, the reaction was expressed and conversion was defined by Eqs. (1) and (2), respectively.

$$
\begin{aligned}
& \mathrm{SiH}_{4} \longrightarrow \mathrm{Si} \text { (fines or deposit) }+2 \mathrm{H}_{2} \\
& \mathrm{X}=(\text { Ysi-Yso }) /(\text { Ys+YsYso })
\end{aligned}
$$

When the top surface of the gas injector was 1 ccated $215 \mathrm{~mm}$ below the center of the furnace (type SB), the temperature in the bed mostly increased with the height of the thermocouple and the maximum temperature in the bed was observed by No. 4 thermocouple located $245 \mathrm{~mm}$ above the injector surface. When the top surface of the gas injector was located $140 \mathrm{~mm}$ below the center of the furnace (type LA), the temperature in the bed mostly decreased with the height of the thermocouple and the maximum temperature in the bed was observed by No.2 thermocouple located $95 \mathrm{~mm}$ above the injector surface. In the following discussion, the maximum temperature in the bed was used as the representative temperature.

4.- Effects of temperature and distributor design.

\begin{tabular}{|c|c|c|c|c|}
\hline & run 018 & $\begin{array}{c}C s \\
\{\%] \\
\left\{\begin{array}{l}\% .1 \\
2.1\end{array}\right.\end{array}$ & $\underset{[1 / \min ]}{Q 0}$ & $\mathrm{Qs}_{11 / \mathrm{min}}$ \\
\hline 口 & run 022 & 16.4 & 13.3 & 2.60 \\
\hline 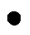 & run $128 \mathrm{~A}$ & 12.3 & 15.5 & 2.18 \\
\hline$\Delta$ & run $204 \mathrm{~A}$ & 12,3 & 15.5 & 2.18 \\
\hline 0 & run 209A & 12.3 & 15.5 & 2.18 \\
\hline
\end{tabular}

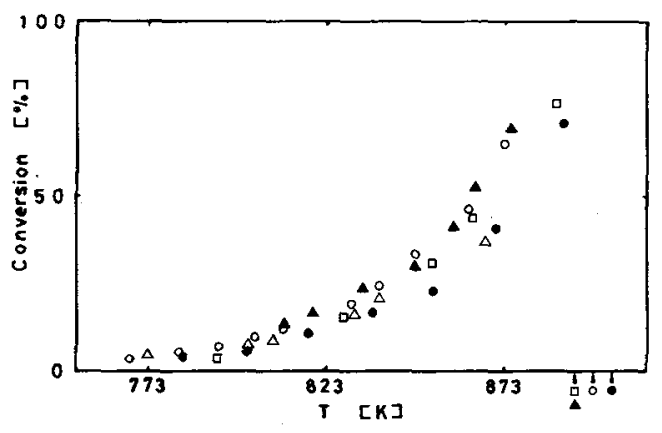

Fig. 4- Effect of temperature on conversion. 
In the present section, the results for the runs No. 018, 022, 128A, 204A and 209A are discussed. In all runs, the monosilane conversion increased with increasing representative bed temperature. The results are shown in Fig. 4. The apparent (overal1) first order reaction rate constant of monosilane pyrolysis in the bed, $k_{a p}$ is expressed as follows.

$$
\mathrm{k}_{\mathrm{ap}}=-\ln (1-X) / \mathrm{t}^{*}
$$

The data in Fig. 4 are re-plotted in the form of an Arrhenius Plot in Fig. 5. The slope of the line in Fig. 5 indicates the overall value of $-E / R$. However, the value includes some errors because of temperature distribution in the bed. In all runs, the apparent activation energy, $\mathrm{E}$, was determined to be $193000 \mathrm{~J} / \mathrm{mol}$. The value of $\mathrm{E}$ was almost same as the value of $191500 \mathrm{~J} / \mathrm{mol}$ obtained as the activation energy of heterogeneous deposition reaction rate constant, from a fixed bed experiment $/ 7 /$. Therefore, the heterogeneous reaction is suggested to be predominant (compared with homogeneous reaction) and is the rate-determining step (compared with mass exchange between bubble and emulsion) in the fluidized bed CVD by monosilane pyrolysis.

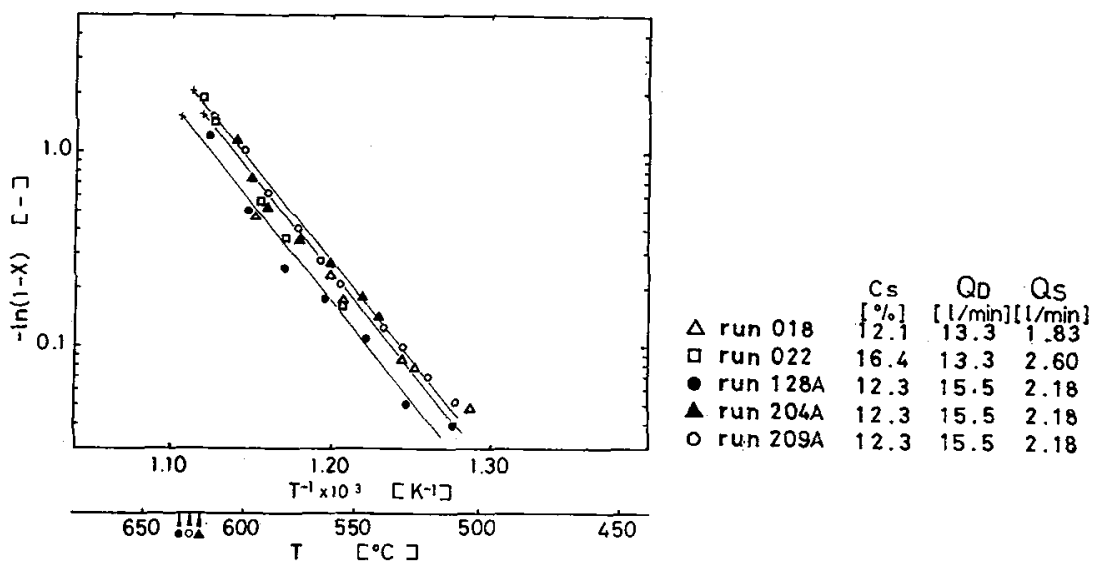

Fig. 5.- Arrhenius plot.

When the bed temperature was gradually increased, the temperature drastically changed at some critical temperature as shown in the previous paper $19 /$. The phenomenon indicates the formation of agglomerates (clogging) between the heights where the temperature increased and decreased. The clogging was usually observed between Nos. 2 and 3 thermocouples for the arrangement "SB" and between Nos. 1 and 2 for "LA". Almost the same agglomeration or clogging temperature was obtained for different heating rates. The clogging temperature is shown on the abscissa and the maximum conversion without clogging was that at " $\mathrm{X}$ " located at the end of the line in Fig. 5. The highest maximum conversion was obtained for run No. 209 where "LAP" arrangement was adopted, namely when the porous plate was located at the higher position in the reactor under the condition of $\mathrm{Uo}=6 \mathrm{Umf}$.

\section{5.- Effects of silane concentration and flow rate.}

The results for the conversion are shown in Fig. 6 for runs No. 204B and No.209B. In both runs, the flow rates of hydrogen and silane were varied at a constant representative temperature of $873 \mathrm{~K}$. Under the condition of Uo $=6 \mathrm{Umf}$, which was almost same flow rate as in the runs discussed above, an increase in the inlet monosilane concentration was difficult because of the clogging.

Under the condition of $\mathrm{Uo}=4 \mathrm{Umf}$, the inlet silane concentration was able to be in- 
creased without clogging, to $64.5 \%$ for run No. $209 \mathrm{~B}$ and to $49.2 \%$ for run No.204B. Additionally, under the condition of $\mathrm{Uo}=4 \mathrm{Umf}$, the conversion of silane was higher than that under the condition of Uo $=6$ Umf for run No. 209B. The conversion was found to increase slightly with increasing inlet silane concentration.

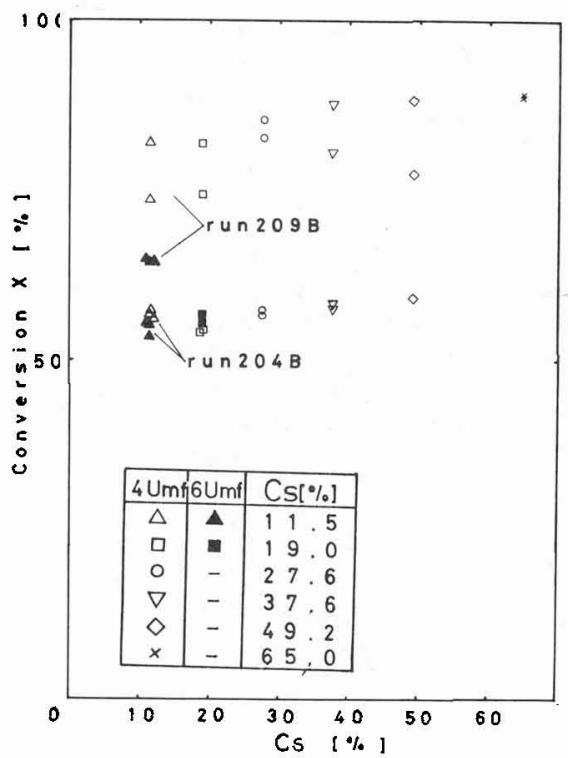

Fig. 6.- Effects of gas flow rate and concentration on conversion.

6.- Long run operation

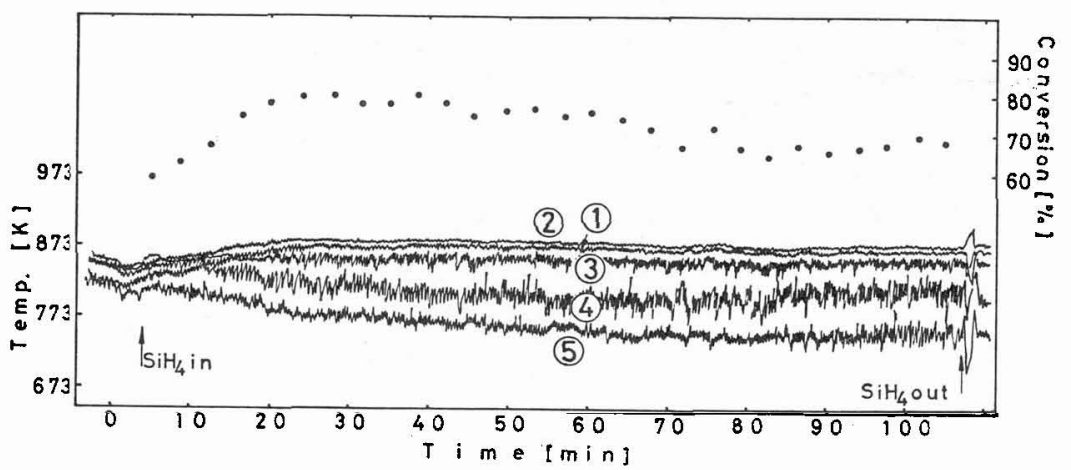

Fig.7- Result on long run operation

From the above results for the runs for determination of operational conditions with high silane conversion and without clogging at relatively high silane concentration, the conditions shown in Table 2 were selected for run No.213. The gas flow rate was $4 \mathrm{Umf}$ (hydrogen flow rate; $5.01 / \mathrm{min}$, silane flow rate: $3.791 / \mathrm{min}$ at $298 \mathrm{~K}$, respectively) and the initial bed height was $278 \mathrm{~mm}$. After the operation at $883 \mathrm{~K}$ $(+/-5 \mathrm{~K}$, maximum temperature in bed) for $16 \mathrm{~min}$ with average conversion of $86.1 \%$, the operation was continued at $873 \mathrm{~K}(+/-5 \mathrm{~K})$ for $103 \mathrm{~min}$. The average conversion was $71.2 \%$ and any trouble such as clogging was not observed. The time variation of silane conversion and the temperature profiles in the bed are shown in Fig. 7. The 
operation was stopped because of the lack of monosilane for feedstock.

The total fed silicon in monosilane was $527.0 \mathrm{~g}$. The fractions of unreacted monosilane, deposit on particles, and fines elutriated (including fines collected from the wall of freeboard of the reactor) were respectively $26.7 \%, 74.0 \%$ and $1.6 \%$. The total mass balance was $101.3 \%$. The ratio of fines formation to the deposition in hydrogen diluent was obviously small compared with previously reported results 15/. This contradiction may be explained by the difference in the temperature profiles, especially in the freeboard, where only homogeneous reaction takes place, and/or by difference in the size distribution of seed particles.

\section{7.- Conclusion.}

The pyrolysis of monosilane diluted with hydrogen was conducted in a batch 50mm ID fluidized bed reactor. The optimum operation condition for high inlet silane concentration, high silane conversion and low fine silicon formation without clogging phenomena was determined from preliminary experiments, varying bed temperature, grid structure and gas flow rates. Lastly continuous operation was conducted for more than $100 \mathrm{~min}$. without any trouble under the optimum condition determined above.

\section{Acknowledgment.}

T.K. wish to express his thanks to Grant-in-Aids for Scientific Researches by the Ministry of Education, Science and Culture, Japan.

Symbols

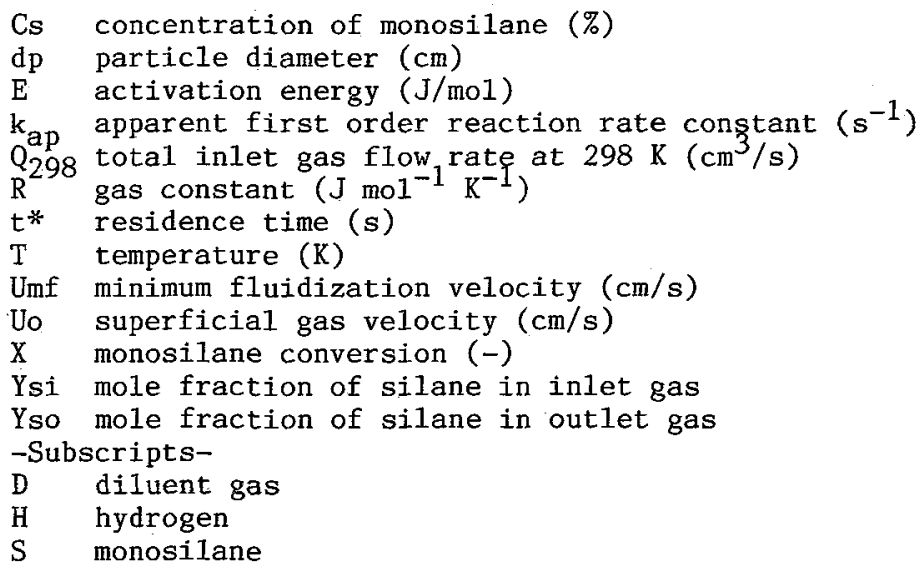

\section{References}

/1/ KOJIMA T., FURUSAWA T., Kagaku Kogaku, 51 (1987) 217.

/2/ NODA T., Proc. Flat Plate Solar Array Project Work Shop, DOE/JPL (1986) p. 213.

/3/ IYA S.K., Proc. Flat Plate Solar Array Project Work Shop, DOE/JPL (1986) p. 135.

/4/ HSU G., Proc. Flat Plate Solar Array Project Work Shop, DOE/JPL (1896) p.187.

/5/ HSU G., HOGLE R., ROHATGI N., MORRISON A., J. Electrochem. Soc., 131 (1984) 660.

/6/ IBRAHIM J., JOHNSTON S.W., Proc. 2nd Symp. Fluidized Bed Process. of Powder Materials, Soc. Chem. Eng. Jpn., (1990) p.26.

/7/ FURUSAWA T., KOJIMA T., HIROHA H., Chem. Eng. Sci., 43 (1988) 2037.

/8/ KOJIMA T., HIROHA H., FURUSAWA T., Kagaku Kogaku Ronbunshu, 16 (1990) 498.

/9/ KOJIMA T., MORISAWA 0., Kagaku Kogaku Ronbunshu, 16 (1990) $6 \frac{16}{6}$. 